$\stackrel{W}{=}$

Global burnals Inc.

है

\title{
Quantitative Outcomes of a One Health Approach to Investigate the First Outbreak of African Swine Fever in the Republic of Sierra Leone
}

By Raoul Emeric Guetiya Wadoum, Dr. Jacqueline Kasiiti Lichoti, Dr. Nantima Noelina, Dr. Bitek Austine, Dr. Leno Amara, Abdul K. Sesay, David Heingola JoJo, Abdulai Mahmood Conteh, Mohamed Haddy Leigh, Joseph Marah, Hawa M. Sesay, Gbassay Caulker, Samuella T. Kanu, Benjamin H. Sesay, Joseph A. Turay \& Dr. Germain BoBo

Mbarara University of Science and Technology

Summary- African swine fever (ASF) outbreaks have been reported in Sub-Saharan countries, including West Africa states, but has never been notified in the Republic of Sierra Leone. This is the first report describing field epidemiological and laboratory investigations into the outbreak of fatal pig disease in western rural and urban districts, Freetown. A preliminary finding indicated that pigs exhibited clinical and necropsy signs suggestive of ASF. Serological (ELISA) and molecular (qRT-PCR) methods used to confirm and investigate the outbreak yielded three positive results for the ASF antibody and all negative for Swine flu; thus, confirming ASF as the etiology agent.

Keywords: one health; zoonotic diseases; african swine fever virus; influenza a viruses; sierra leone.

GJMR-K Classification: NLMC Code: QY 60.S8

Strictly as per the compliance and regulations of:

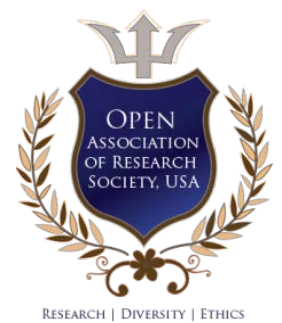

(C) 2020. Raoul Emeric Guetiya Wadoum, Dr. Jacqueline Kasiiti Lichoti, Dr. Nantima Noelina, Dr. Bitek Austine, Dr. Leno Amara, Abdul K. Sesay, David Heingola JoJo, Abdulai Mahmood Conteh, Mohamed Haddy Leigh, Joseph Marah, Hawa M. Sesay, Gbassay Caulker, Samuella T. Kanu, Benjamin H. Sesay, Joseph A. Turay \& Dr. Germain BoBo. This is a research/review paper, distributed under the terms of the Creative Commons Attribution-Noncommercial 3.0 Unported License http://creativecommons.org/licenses/by-nc/3.0/), permitting all non-commercial use, distribution, and reproduction in any medium, provided the original work is properly cited. 


\title{
Quantitative Outcomes of a One Health Approach to Investigate the First Outbreak of African Swine Fever in the Republic of Sierra Leone
}

\author{
Raoul Emeric Guetiya Wadoum ${ }^{\alpha}$, Dr. Jacqueline Kasiiti Lichoti ${ }^{\circ}$, Dr. Nantima Noelina ${ }^{\rho}$, \\ Dr. Bitek Austine ${ }^{\omega}$, Dr. Leno Amara ${ }^{*}$, Abdul K. Sesay ${ }^{\S}$, David Heingola JoJo ${ }^{x}$, \\ Abdulai Mahmood Conteh ${ }^{\vee}$, Mohamed Haddy Leigh ${ }^{\ominus}$, Joseph Marah ${ }^{\zeta}$, Hawa M. Sesay ${ }^{\ddagger}$, \\ Gbassay Caulker ${ }^{\ddagger}$, Samuella T. Kanu ${ }^{\mp}$, Benjamin H. Sesay ${ }^{z}$, Joseph A. Turay ${ }^{\ddagger} \&$ Dr. Germain BoBo ${ }^{\circledR}$
}

Summary- African swine fever (ASF) outbreaks have been reported in Sub-Saharan countries, including West Africa states, but has never been notified in the Republic of Sierra Leone. This is the first report describing field epidemiological and laboratory investigations into the outbreak of fatal pig disease in western rural and urban districts, Freetown. A preliminary finding indicated that pigs exhibited clinical and necropsy signs suggestive of ASF. Serological (ELISA) and molecular (qRT-PCR) methods used to confirm and investigate the outbreak yielded three positive results for the ASF antibody and all negative for Swine flu; thus, confirming ASF as the etiology agent. The One Health Multisectoral approach adopted during this investigation involving the Ministry of Agriculture and Forestry, the Ministry of Health and Sanitation, the University of Makeni, Njala University, and other partners proved to be an effective outbreak response strategy and alleviate fear and panic through community engagement and sensitization.

Corresponding Author $\alpha$ : Department of Public Health, University of Makeni, Makeni, Sierra Leone and Department of Public Health, Ernest Bai Koroma University of Science and Technology, Sierra Leone, Food and Agriculture Organization of the United Nations (FAO) Sierra Leone country Office.e-mail: raoulemeric@gmail.com

Corresponding Authors $\sigma$ A: FAO and Livestock and Veterinary Services Division, Ministry of Agriculture and Forestry, Sierra Leone. e-mails: Jacqueline.Lichoti@fao.org, Germain.Bobo@fao.org

Author $\rho \omega$ : FAO and Livestock and Veterinary Services Division, Ministry of Agriculture and Forestry, Sierra Leone.

Author \&: Directorate of Health Security and Emergencies, Ministry of Health and Sanitation, Sierra Leone.

Author x: Department of Animal Sciences, Njala University, Sierra Leone. Author v: Department of Animal Sciences, Njala University, Sierra Leone.

Author $\theta$ : Directorate of Livestock and Veterinary Services, Ministry of Agriculture and Forestry, Sierra Leone.

Author द: Department of Public Health, University of Makeni, Makeni, Sierra Leone.

Author f: Department of Public Health, University of Makeni, Makeni, Sierra Leone

Author $€$ : Department of Public Health, University of Makeni, Makeni, Sierra Leone.

Author F: Department of Public Health, University of Makeni, Makeni, Sierra Leone.

Author z: Department of Public Health, University of Makeni, Makeni, Sierra Leone.

Author \$: Department of Public Health, University of Makeni, Makeni, Sierra Leone.
Keywords: one health; zoonotic diseases; african swine fever virus; influenza a viruses; sierra leone.

\section{INTRODUCTION}

$\wedge$ frican swine fever (ASF) is a significant disease of domestic pigs caused by a DNA arbovirus virus belonging to the family Asfaviridae (Dixon et al., 2005). To date, there are 22 different genotypes described based on the p72 sequences, all of which circulate on the Africa continent (Boshoff et al., 2007). Due to its devastating economic impact in affected countries, the World Organization for Animal Health (OIE) listed ASF as a notifiable disease.

Outbreaks of ASF have been reported in SubSaharan countries, including West Africa states particularly in Benin, Burkina Faso, Cote d'Ivoire, the Gambia, Ghana, Guinea, Guinea-Bissau, Mali, Nigeria, Senegal, and Togo; however, the Republic of Sierra Leone never reported an epidemic of ASF [Bastos et al., 2003; Brown et al., 2018; Penrith et al., 2013]. Nonetheless, the Ministry of Agriculture and Forestry (MAF), together with the Ministry of Health and Sanitation (MoHS) jointly announced on 23 October 2019 that an outbreak of an unknown disease was killing pigs in western rural and urban districts, Freetown. Preliminary investigation jointly conducted by MAF and the Food and Agriculture Organization of the United Nations (FAO) in the affected areas, indicated that pigs exhibited clinical signs matching suspect case definition for ASF as defined by OIE which included; high fever, depression, loss of appetite, hyperemia and cyanosis (seen as reddening) of the skin, particularly the ears and snout and eventually death.

Recognizing that pigs host various zoonotic pathogens, One Health $(\mathrm{OH})$ approach aligned with global recommendation was established and implemented to investigate the etiological agents responsible for the epidemic, and institute prevention and control measures. $\mathrm{OH}$ approach promoted interdisciplinary collaboration and coordination, bringing 
together health scientists and practitioners at the human, animal, and environment to strengthen emerging and re-emerging infectious disease surveillance and outbreak response.

Consequently, a $\mathrm{OH}$ rapid response team composed of epidemiologists from MAF, MoHS, FAO, and scientists from the University of Makeni, Njala University and CDC/AFFENET/FELTP intermediate students was deployed in affected communities to gather epidemiological information (morbidity, mortality and cases fatality rates, risk factors) in affected and unaffected farms, collect biological samples for laboratory confirmation and institute prevention and control measures to contain the outbreak.

Here we report preliminary field epidemiological and laboratory investigations findings into the first outbreak of ASF in the Republic of Sierra Leone.

\section{Materials and Methods}

\section{a) Localization of the study}

Investigations were carried out from 29 October to 1 November 2019 by three sub teams derived from the One Health rapid response team. Each team was assigned communities where reports of death pigs had occurred to undertake active disease searches to identify cases using case definition for ASF provided by FAO. The case definition used was any pig herd with one or more age groups affected with high fever, depression, and loss of appetite, hyperemia, and cyanosis of the skin, particularly at the ears and snout and eventually death within 2-10 days in the affected areas from $10^{\text {th }}$ September 2019 to present.

Areas visited included Monkey Bush, Campbell Town, Samuel Town in Waterloo, Maburieh, Bengumah, Ibo Town, Bomeh in waterloo, Bomeh/Kingtom, Kroobay, Susan Bay, Moawharf and Racecourse Clintown (Figure 1). Each investigation team received forms/questionnaires for collecting epidemiological and laboratory data, and case definition checklist to assist them to identify cases.

\section{b) Sample Collection}

Infected and non-infected farms were visited for inspection and specimen recovered from more than 60 pigs of ages between 4 -12 months. Moreover, each team recorded GPS coordinate of various communities visited during the five days of field activities. For each pig, oral pharyngeal swabs, nasal mucosae swabs were collected using sterile swab collection kits and placed in $2 \mathrm{~mL}$ cryovial containing RNAlater (Ambion Inc., Austin, TX, USA). Cardiac puncture method was used for blood sample collection into a vacutainer tube with or without containing EDTA and plasma or serum recovered and stored until analysis. Fecal samples and tissues (spleen, liver, lymph nodes, lungs, heart, and kidneys) from dead pigs at postmortem were also collected.
During field expedition, scientists kept all samples on dry ice, and upon returning to the laboratory they were transferred to $\mathrm{a}-20{ }^{\circ} \mathrm{C}$ freezer then $-80^{\circ} \mathrm{C}$ until further analysis.

All specimens were collected in duplicate and transported to Central Veterinary Laboratory (CVL), Teko Makeni for testing for ASF, and to the University of Makeni Infectious Diseases laboratory (IDRL) for Swine Flu and other potential zoonotic diseases analysis.

\section{c) Serology assay for detection of ASF}

All serum and blood samples were analyzed using a Multi-antigen indirect ELISA kit for the detection of ASF antibodies against P32, P62, and P72 ASF antigens manufactured by ID Vet diagnostics (ID Vet, 2019). Briefly, samples were added to the antigen precoated plate and incubated at room temperature, after washing to eliminate excess serum, a specific conjugate was added and incubated. The plates were further washed, and upon addition of substrate and stop solution respectively, incubated and optical density read on a Multiskan Sky Microplate Spectrophotometer (ThermoFisher Scientific).

\section{d) Detection of Swine Flu \\ i. RNA Extraction and $q R T-P C R$}

RNA from oral swabs, nasal swabs, serum, and plasma was extracted using QiaAmp Viral RNA Mini Kit (Qiagen, Hilden, Germany) following manufacturer's instruction and material eluted in 60 $\mu \mathrm{L}$ of AVE buffer and stored at $-80{ }^{\circ} \mathrm{C}$ until needed. Quantitative reverse transcription real-time PCR (qRT-PCR) for the detection of Human Influenza $\mathrm{A} \mathrm{H} 1$ and $\mathrm{H} 3$ viruses was performed on a Light Cycler ${ }^{\circledR} 96$ Instrument (Roche, Life Science) using a Primer Design ${ }^{\mathrm{TM}}$ genesig kit (Southampton, United Kingdom) following the manufacturer's instruction with cut-off $\mathrm{Ct}$ set at 38. The PCR amplification reaction was performed in a $20 \mu \mathrm{L}$ reaction mix as follows; $50{ }^{\circ} \mathrm{C}$ for $600 \mathrm{~s}$ (reverse transcription) and $95{ }^{\circ} \mathrm{C}$ for $15 \mathrm{~min}$ (DNA polymerase activation), followed by 50 cycles at $95{ }^{\circ} \mathrm{C}$ for $10 \mathrm{~s}$ (denaturation), and finally $60{ }^{\circ} \mathrm{C}$ for $60 \mathrm{~s}$ (annealing and extension). Positive results obtained were characterized by a sigmoid curve, showing an initial, rapid, exponential increase in fluorescence signal followed by a plateau. Negative reactions did not show any increase in fluorescence signal. A standard curve was created automatically with the Light Cycler ${ }^{\circledR}$ software in each run by plotting the cycle threshold number against the copy numbers of each standard, and quantification of unknown samples were inferred from the regression line.

\section{e) Data Analysis}

Microsoft excel was used for all analyses and animal-related factors characterizing animals or herd such as breed, age, herd size, grazing system, morbidity, mortality, and breeding system were established through univariate analysis. 
Recent and past exposure to ASF was determined by the presence of ASF specific antibodies, and seroprevalence defined as the proportion of positive ASF IgG/IgM antibodies among the sampled pigs, and molecular assay data analysis performed on the LightCycler® 96 Application Software Version 1.1.

\section{ili. Results and Discussion}

Pig production in Sierra Leone is mainly smallscale traditional using indigenous breeds of pigs, which are small, short, and sturdy with little hair covering on the skin. Some farmers keep exotic breeds, mainly large white race, and Duroc. There has been a lot of crossbreeding between the local and the exotic breeds, giving rise to hybrids. The country has an estimated pig population of 57,877 pigs representing $1 \%$ of the total livestock population in the country (Table 1). Western Urban and Western areas have an estimated pig population of 4,343 and 6,603 respectively representing about $20 \%$ of the total pig population in the country.

The $\mathrm{OH}$ teams visited 48 households in 12 communities in Monkey Bush, Campbell Town, Samuel Town in Waterloo, Maburieh, Bengumah, Ibo Town, Bomeh in waterloo, Bomeh/Kingtom, Kroobay, Susan Bay, Moawarf and Racecourse. The majority of the pig farmers visited were keeping pigs on the free-range system, and they were roaming and scavenging under very poor hygienic conditions. Also, the farmers were dumping dead pigs in the nearby streams/tributaries where other pigs were scavenging, which increased the risk for ASF spreading to others districts such as Port Loko and Tonkolili; thus, representing a major risk of contamination in those districts.

Studies have highlighted that indiscriminate disposal of pig viscera, waste materials, poor biosecurity measures and salvage sale of survivor and sick pigs without testing contribute to in-country maintenance and spread of ASF (Kabuuka et al., 2014; Muhangi et al., 2015; Nantima et al., 2015).

The estimated herd mortality in the sampled households ranged from 0 to $99.4 \%$. The mortality rate was highest in local communities within the Western Urban district compared to the Western Rural district (Table 2). Kroobay in Western Urban had the highest herd mortality rate of $99.4 \%$ while Colvert and Benguima in Western Rural districts had 0\% herd mortalities. These mortality disparities are concordant with previous studies indicating that ASF mortality varies between 30$70 \%$ for moderately virulent strains and $100 \%$ in naïve herds of domesticated pigs (Spickler, 2019).

Three hundred and thirty-nine (339) specimens were collected during investigation including, whole blood, serum, oral swabs, nasal swabs, fecal samples, and organs. The samples collected included; whole blood, serum, nasal and oral pharyngeal swabs as well as fecal samples. A post-mortem was undertaken on dead pigs, and organs collected, including spleen, lymph nodes, kidneys, liver, and heart.

Among the samples collected during the investigation, ASF ELISA detected antibodies in three samples from sick pigs (2 URC serum and 1 UKT (blood and serum)), indicative of exposure to the ASF virus (Table 3). Currently, there is no vaccine against ASF; therefore, the presence of antibodies in sick pigs is a result of exposure to the ASF virus. The behavior of farmers quickly selling off sick pigs to mitigate economic impact compromised the detection of virus and antibodies. By the time the response team arrives for investigation, most of the farmers didn't have sick animals. Also, most pigs sampled may not have been exposed to ASF, reason for a large number of negative samples. Considering the epidemiologic features of communities where the massive death of pigs occurred, the most probable source of infection suggested was through virus-contaminated pork products. OIE terrestrial manual for diagnostics of ASF recommends that investigation of new outbreaks should include the detection of specific antibodies in serum or extracts of tissues (OIE, 2019). These results confirmed the initial suspicion of ASF being the etiology agent responsible for the outbreak.

Even though findings confirmed ASF as the leading etiology of the outbreak, concerns raised about pigs been co-infected with other zoonotic disease were legitimate given that pigs are known to be susceptible to zoonotic diseases such as Ebola virus disease (Reston ebolavirus) and Swine flu (CDC, 2019; Nelson et al., 2019). Accordingly, a total of 204 RNA derived from oral swabs, nasal swabs, and serum/plasma were screened by qRT-PCR for the detection of Human Influenza A H1 and $\mathrm{H} 3$ gene. Results reveal that no amplification was produced in the no-template control reaction wells while positive control used as standard at various concentration upon amplification, yielded a typical sigmoidal curve; thus, validating the assay. However, all samples tested were negative, with the amplification curve failing to display sigmoidal curves as positive control. Presently, the laboratory diagnosis of influenza virus infection in pigs typically relied upon the detection of the virus in nasal swabs. Serology to detect antibodies is of low value for swine Influenza virus surveillance because vaccination against the disease rely on inactivated $\mathrm{H} 1 \mathrm{~N} 1$ and $\mathrm{H} 3 \mathrm{~N} 2$ vaccines, and current serologic tests do not differentiate between vaccinated and infected animals (Detmer et al., 2013). Therefore, virological assays are currently preferred over serology for surveillance. In the current study, Human influenza $A$ virus $\mathrm{H} 1$ and $\mathrm{H} 3$ weren't detected in the various samples analyzed; thus, supporting that pigs weren't co-infected with the Swine flu virus. Nevertheless, the non-detection of these viruses was crucial as appropriate information was tailored and provided to decrease public fear of the zoonotic 
potential of the outbreak in Freetown. The intensive community sensitization by the $\mathrm{OH}$ teams was satisfactory as farmers were engaged about issues of implementing biosecurity measures and had to bury and burn dead pigs in some localities. Some farmers that still had few pigs surviving was advised on the benefit of isolating sick pigs even though most farmers reported to have lost all their pigs.

Sierra Leone has never reported an outbreak of African swine fever. During the epidemiological investigations, some farmers revealed that they experienced an outbreak similar to this one about three years ago. It is possible that outbreaks have been occurring without being reported to Livestock and Veterinary Services Division of MAF, or no response was provided by the weak Veterinary service of Sierra Leone.

The major risk factors that could have exacerbated the spread of ASF during this outbreak were selling sick and dead pigs by the affected farmers, disposal of dead pigs in the streams/tributaries where other pigs were scavenging, and inadequate biosecurity measures. These could have been among the reasons why the disease was more severe in localities in Western Urban compared to Western Rural district.

There is no specific policy for controlling ASF in Sierra Leone. The control of ASF is governed under the Animal Diseases Ordinance (1948). The challenge is that most of the legislation is outdated and therefore lacks relevant provisions in controlling the disease. The old law is currently being revised, and hopefully, the new law will address ASF control. The country does not have a compensation policy to support farmers that have lost pigs to ASF. Also, there is no surveillance study related to ASF, and other pig diseases currently being carried out in the country.

\section{Conclusion}

Our findings confirmed ASF as the etiology of the reported outbreak of ASF in the republic of Sierra Leone. We demonstrated that rapid response and community engagement following the One Health approach is an effective means to alleviate fear and panic during an outbreak.

\section{Recommendations}

1. African Swine Fever is a notifiable disease in Sierra Leone, and the Government should urgently notify OIE and RECs about the outbreak

2. A program to train farmers on implementation of biosecurity practices should immediately be undertaken by Government

3. Adequate community engagement in future should be undertaken before investigations to improve compliance by the farmers and communities

4. There should be a rapid response to outbreaks by Government to mitigate the impact from such outbreaks
5. A strategy for ASF control should be developed and implemented

6. The One Health Multisectoral approach adopted during this investigation involving; MAF, MOHS, UNIMAK, Njala University, and other partners should be continued and cascaded to other outbreak investigations.

7. Security personnel should be included especially while investigating an outbreak associated with high mortality rates

8. Training of investigation teams in basic skills of Biosafety and biosecurity, use of PPEs, sample labeling, collection, transportation, processing, and storage should be provided to the teams in future before investigation

9. The government should provide feedback to the farmers after testing the samples to improve compliance in future

10. Assembly of emergency sampling equipment for a timely and quick response

11. Emergency funds for rapid response to an outbreak

\section{Ethics Statement}

The authors confirm that the ethical policies of the journal, as noted on the journal's author guidelines page, have been adhered to. No ethical approval was required as this was the Sierra Leone government investigation into the outbreak. However, animal handling and sample collection respected the rules formulated under the Animal Welfare Act by the United States Department of Agriculture (USDA) and by adopting ARRIVE guidelines (Kilkenny et al., 2011).

\section{ACKNOWLeDgments}

We thank the Western Urban and Rural districts community stakeholders for their support and for allowing us to perform sampling; officers of the Ministry of Health and Sanitation, Ministry of Agriculture and Forestry; the Food and Agriculture Organization of the United Nations including Dr. Mohamed Vandi, Dr. Amadu Tejan Jalloh, Sorie Kamara, Bayoh Musa, Tommy Josephine; Minkailu, field teams including Mary, Satta, Zainabu, Leigh, Kadijja Kamara, Bintah Bah, Bangura, Ishmail, Lamin Bangura, Mohamed Jalloh, Hajja Bah, Saidu AB Turay, Christian Scoff, Fafia Bona, and Alhassan Jalloh for participating in community engagement and supporting sample collection.

\section{Conflict of Interest}

The authors declare that there are no conflicts of interest regarding the publication of this paper.

\section{Funding Statement}

This work was supported by the Food and Agriculture Organization of the United Nations, Sierra Leone. 


\section{References Références Referencias}

1. Dixon, L. K., Escribano, J. M., Martins, Rock, D. L., Salas, M. L., Wilkinson, P. J. (2005). Asfarviridae. In: C. M. Fauquet \& M. A. Mayo (Eds.), Virus taxonomy. Elsevier/Academic Press; 2005. p. 135-43.

2. Boshoff, C. I., A. D. S. Bastos, L. J. Gerber, and W. Vosloo. (2007). Genetic characterization of African swine fever viruses from outbreaks in southern Africa (1973-1999). Vet. Microb, 121, 45-55.

3. Bastos, A. D., Penrith, M., Cruciere, C., Edrich, J., Hutchings, G.,......Thomson, G. R. (2003). Genotyping field strains of African swine fever virus by partial p72 gene characterization. Archives of Virology, 148, 693-706.

4. Penrith, M., Vosloo, W., Jori, F., \& Bastos, A. D. (2013). African swine fever virus eradication in Africa. Virus Research, 173, 228-246.

5. Brown A-A, Penrith ML, Fasina FO, Beltran-Alcrudo D. (2018). The African swine fever epidemic in West Africa, 1996-2002. Transbound Emerg Dis, 65, 6476. https://doi.org/10.1111/tbed.12673

6. ID Vet Diagnostics. https://www.id-vet.com/produit /id-screen-african-swine-fever-indirect/

7. Kabuuka, T., Kasaija, P. D., Mulindwa, H., Shittu, A., Bastos, A. D. S., \& Fasina, F. O. (2014). Drivers and risk factors for circulating African swine fever virus in Uganda, 2012-2013. Research in Veterinary Science, 97, 218-225.

8. Muhangi, D., Masembe, C., Emanuelson, U., Boqvist, S., Mayega, L.,.....Stahl, K. (2015). A longitudinal survey of African swine fever in Uganda reveals high apparent disease incidence rates in domestic pigs, but absence of detectable persistent virus infections in blood and serum. BMC Veterinary
Research, 11, 106. https://doi.org/10.1186/s12917015-0426-5

9. Nantima, N., Ocaido, M., Ouma, E., Davies, J., Dione, M., .......Bishop, R. (2015). Risk factors associated with occurrence of African swine fever outbreaks in smallholder pig farms in four districts along the Uganda-Kenya border. Tropical Animal Health and Production, 47, 589-595. https:// doi.org/10.1007/s11250-015-0768-9.

10. Spickler Anna Rovid. (2019). African Swine Fever. Center for Food Security and Public Health. Retrieved from http://www.cfsph.iastate.edu/ Diseaselnfo/factsheets.php.

11. OIE Manual of Diagnostic Tests and Vaccines for Terrestrial Animals 2019. Retrieved from https://www.oie.int/fileadmin/Home/eng/Health_stan dards/tahm/3.08.01_ASF.pdf

12. Nelson, M. I., Souza, C. K., Trovão, N. S., Diaz, A., Mena, I.,..........Culhane, M. R. (2019). Human-Origin Influenza $\mathrm{A}(\mathrm{H} 3 \mathrm{~N} 2)$ Reassortant Viruses in Swine, Southeast Mexico. Emerging Infectious Diseases, 25, 691-700. https://dx.doi.org/10.3201/eid2504. 180779.

13. Centers for diseases control and prevention. https://www.cdc.gov/vhf/ebola/resources/virusecology.html. Accessed 14 November 2019.

14. Detmer S, Gramer M, Goyal S, Torremorell M, Torrison J. (2013). Diagnostics and surveillance for swine influenza. Curr Top Microbiol Immunol, 370, 85-112. doi: 10.1007/82 2012220 PMID: 22566130

15. Kilkenny, C., Browne, W., Cuthill, I. C., Emerson, M., Altman, D. G. (2011). "Animal research: reporting in vivo experiments-the ARRIVE guidelines". Journal of Cerebral Blood Flow \& Metabolism, 31, 991-993.

Table 1: Livestock population data in Sierra Leone

\begin{tabular}{|c|c|c|c|c|c|c|c|}
\hline District name & Province & Poultry & Cattle & Donkeys & Goats & Pigs & Sheep \\
\hline Kailahun & Eastern & 363,690 & 3,289 & 48386 & 75,090 & 8,645 & 36,173 \\
\hline Kenema & Eastern & 284,730 & 2,308 & 33193 & 27,272 & 2,493 & 19,799 \\
\hline Kono & Eastern & 233,799 & 40,051 & 26793 & 69,082 & 4,765 & 45,637 \\
\hline Bombali & Northern & 355,298 & 47,592 & 17025 & 78,727 & 3,190 & 56,684 \\
\hline Kambia & Northern & 402,805 & 16,375 & 34167 & 63,983 & 1,755 & 50,719 \\
\hline Koinadugu & Northern & 374,373 & 309,291 & 22298 & 212,634 & 2,892 & 191,788 \\
\hline Port Loko & Northern & 602,327 & 20,105 & 57607 & 92,740 & 4,801 & 68,581 \\
\hline Tonkolili & Northern & 384,659 & 9,852 & 56268 & 68,086 & 4,380 & 41,473 \\
\hline Bo & Southern & 307,955 & 4,931 & 23511 & 30,643 & 6,166 & 13,303 \\
\hline Bonthe & Southern & 191,121 & 1,584 & 13719 & 20,369 & 1,588 & 9,967 \\
\hline Moyamba & Southern & 346,812 & 2,464 & 21434 & 42,286 & 4,918 & 15,206 \\
\hline Pujehun & Southern & 220,030 & 720 & 18563 & 15,598 & 1,338 & 10,206 \\
\hline Western Area/Rural & Western Area & 203,106 & 5,241 & 16950 & 13,876 & 6,603 & 10,763 \\
\hline Western Area/Urban & Western Area & 65,644 & 2,014 & 6189 & 3,883 & 4,343 & 4,407 \\
\hline Total & & $4,336,349$ & 465,817 & 396,103 & 814,269 & 57,877 & 574,706 \\
\hline
\end{tabular}


Table 2: Morbidity and Mortality in affected communities

\begin{tabular}{|c|c|c|c|c|c|c|c|c|c|c|c|}
\hline \multirow{3}{*}{ District } & \multirow{3}{*}{ Community } & \multicolumn{4}{|c|}{ Number of Suspect Cases } & \multicolumn{4}{|c|}{ Number of deaths } & \multirow{3}{*}{$\begin{array}{l}\text { Total } \\
\text { Herd } \\
\text { Size }\end{array}$} & \multirow[t]{3}{*}{$\begin{array}{c}\text { Mortality } \\
\text { (\%) }\end{array}$} \\
\hline & & \multicolumn{2}{|c|}{ Adults } & \multicolumn{2}{|c|}{ Young } & \multicolumn{2}{|c|}{ Adults } & \multicolumn{2}{|c|}{ Young } & & \\
\hline & & Males & Females & Males & Females & Males & Females & Males & Females & & \\
\hline Western Urban & Kanikay & 1 & 1 & 1 & 2 & 5 & 5 & 15 & 10 & 40 & $88 \%$ \\
\hline Western Urban & Kroo Bay & 0 & 0 & 0 & 0 & 4 & 3 & 0 & 0 & 7 & 99.4 \\
\hline Western Urban & Susans Bay & 0 & 1 & 0 & 0 & 4 & 3 & 0 & 0 & 8 & $88 \%$ \\
\hline Western Rural & Benguima & 2 & 12 & 10 & 21 & 0 & 0 & 0 & 0 & 45 & $0 \%$ \\
\hline Western Rural & Bomeh & 86 & 93 & 97 & 80 & 86 & 89 & 87 & 65 & 685 & $48 \%$ \\
\hline Western Rural & Bomeh & 2 & 9 & 0 & 1 & 0 & 0 & 2 & 2 & 16 & $25 \%$ \\
\hline Western Rural & Colvert & 0 & 0 & 2 & 6 & 0 & 0 & 0 & 0 & 8 & $0 \%$ \\
\hline Western Rural & Ibu Town & 1 & 1 & 1 & 0 & 2 & 2 & 0 & 0 & 7 & $57 \%$ \\
\hline Western Rural & $\begin{array}{c}\text { Last } \\
\text { Banking }\end{array}$ & 6 & 9 & 10 & 7 & 3 & 3 & 3 & 2 & 36 & $31 \%$ \\
\hline Western Rural & Mabureh & 0 & 1 & 0 & 0 & 2 & 7 & 0 & 0 & 10 & $90 \%$ \\
\hline \multirow[t]{2}{*}{ Western Urban } & Kingtom & 40 & 58 & 30 & 28 & 60 & 75 & 31 & 35 & 415 & $48.4 \%$ \\
\hline & Total & 138 & 185 & 151 & 145 & 166 & 187 & 138 & 114 & 1277 & $52.3 \%$ \\
\hline
\end{tabular}

Table 3: Detection of ASF antibodies in samples using iELISA

\begin{tabular}{|c|c|c|c|c|c|}
\hline Sampling Area & Code & $\begin{array}{c}\text { Type of } \\
\text { Sample }\end{array}$ & Positive & Negative & $\begin{array}{c}\text { Total } \\
\text { samples }\end{array}$ \\
\hline Urban Racecourse & URC & Serum & 2 & 21 & 23 \\
Urban Kingtown & UKT & Serum & 1 & 2 & 3 \\
Urban Kingtown & UKT & Blood & 1 & 2 & 3 \\
Urban Kanikay & UKN & Serum & 0 & 1 & 1 \\
Rural Monkey Bush & RMB & Serum & 0 & 14 & 14 \\
Urban Kroobay & UKB & Serum & 0 & 1 & 1 \\
Rural Campbell & & & & & \\
Town & RCT & Serum & 0 & 3 & 3 \\
Rural Bomeh & RBe & Serum & 0 & 6 & 6 \\
Rural lbo & RIB & Serum & 0 & 1 & 1 \\
Bengumah & BE & Serum & 0 & 7 & 7 \\
Bengumah & BE & Blood & 0 & 13 & 13 \\
Mabureh & MA & Serum & 0 & 8 & 8 \\
Mabureh & MA & Blood & 0 & 13 & 13 \\
\hline
\end{tabular}




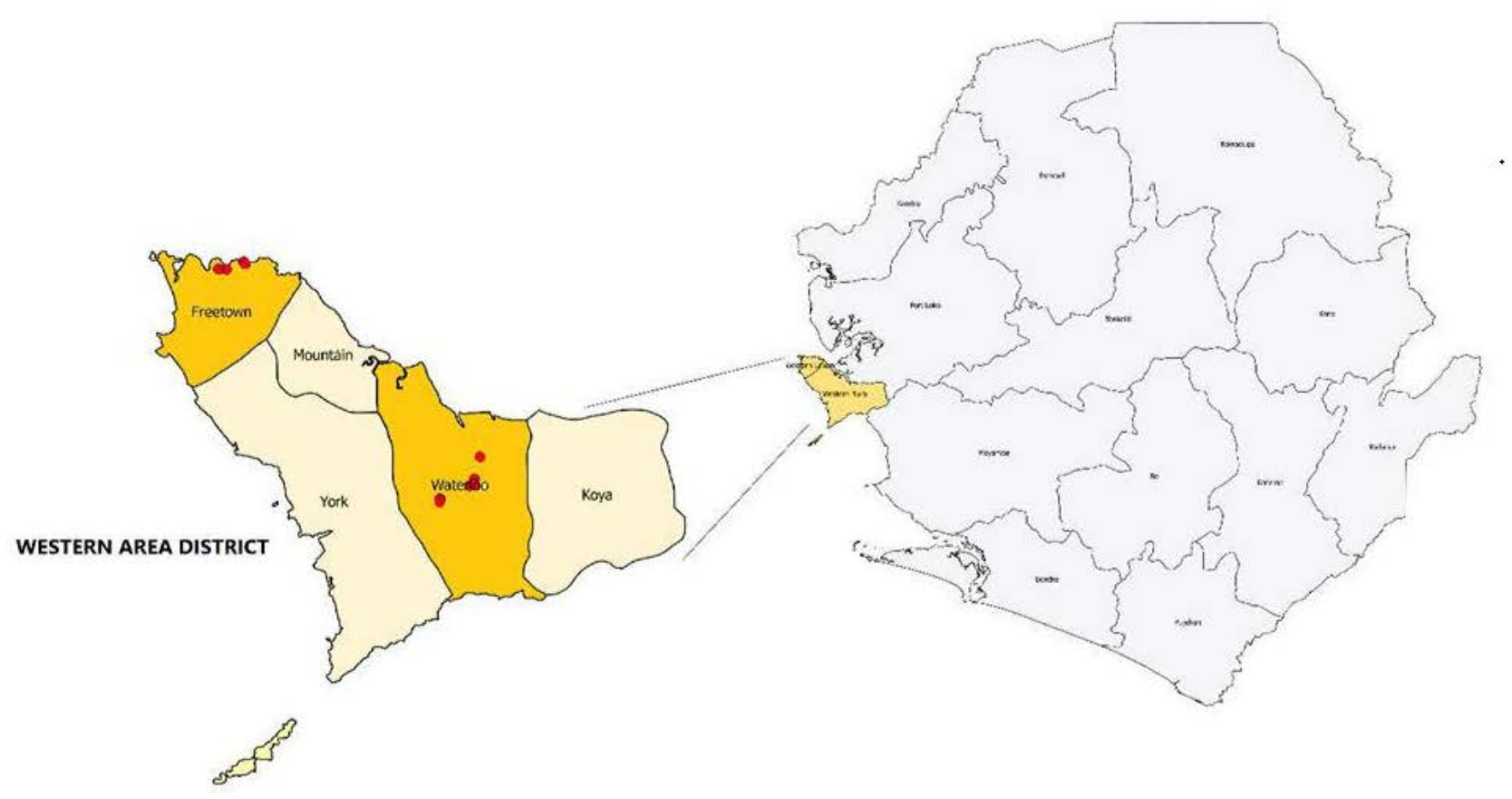

Figure 1: Localities where investigations were conducted in the Republic of Sierra Leone 